\title{
Defluoridation of Domestic Waste water by Using Activated Diatomaceous Earth in Fixed Mattress Column Adsorption System
}

\author{
PAWAN KUMAR $^{1 *}$ and PANKAJ GUPTA ${ }^{1}$ \\ ${ }^{1}$ Research Scholar, Department of Chemistry, Sunrise University, Alwar, Rajasthan, India. \\ ${ }^{1}$ Faculty of Science, Sunrise University, Alwar, Rajasthan, India. \\ ${ }^{*}$ Corresponding author E-mail: kvspwn@gmail.com \\ http://dx.doi.org/10.13005/ojc/370311
}

(Received: May 15, 2021; Accepted: June 17, 2021)

\begin{abstract}
Study aims to eliminate fluoride from treated waste water or ground water through adsorption technique by using activated diatomaceous earth as a sorbent. Study found that there is no change in $\mathrm{pH}$ and TDS, but the concentration of Fluoride ions reduced. The most elimination potential of $71.97 \mathrm{mg} / \mathrm{kg}$ turned into achieved for activated diatomaceous earth with particle sizes of 0.075-0.425 $\mathrm{mm}$. The absorbance capability of diatomaceous earth (DE) is $20.73 \%$ when used as a filtration media. In this analysis, activated diatomaceous earth was used as an adsorbent in a fixed-mattress column adsorption system for DE fluoridation of water. The XRD, BET surface area, FTIR, XRF, Scanning Electron Microscopy (SEM), and pH Point of Zero Charges (pHPZC) evaluation had been executed for adsorbent to explain the mechanisms of absorption and fluoride elimination. The Bradley equation was used to calculate the isothermal data and adsorbent dose. The statistical analyses were performed using Langmuir and Freundlich equations.
\end{abstract}

Keywords: Activated Diatomaceous Earth, Adsorbent, Waste Water, Defluoridation.

\section{INTRODUCTION}

For the vast majority of rural communities in countries such as India, the most favored source of drinking water is groundwater. For healthy teeth, fluoride levels in portable water should be between $0.5-1.0 \mathrm{mg} / \mathrm{L}$ as described by WHO. "In India, fluoride levels in portable water between $1.0-1.5 \mathrm{mg} / \mathrm{L}$, higher fluorides more than $1.5 \mathrm{mg} / \mathrm{L}$ concentrations in human consumable water have been shown dental and skeletal fluorosis"1. Fluoride has been shown to disrupt nutrient, enzyme, protein, lipid, carbohydrate and mineral metabolism when consumed in large doses. The kidney and other internal parts of the body are also affected. Defluoridation can be done in a variety of ways. The adsorbent is the most important part of an adsorption-based defluoridation system. The ability of a variety of adsorbents, both natural and modified, to remove fluoride has been investigated. The capacity for defluoridation by natural and synthetic materials has been investigated. Activated alumina, natural and metal oxide-modified bentonite clay, activated coconut charcoal, surfacetailored zeolite, lanthanum hydroxide, and synthetic

This is an Open Access article licensed under a Creative Commons license: Attribution 4.0 International (CC- BY). Published by Oriental Scientific Publishing Company @ 2018

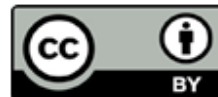


hydroxyapatite are just a few examples. There is no end to the research into potential defluoridation products. It is preferable for a material used as an adsorbed to be easily available in local market, plentiful, and inexpensive. Diatomaceous earth (DE) is a successful materials for investigation because of these factors. DE is non-toxic and plentiful in nature. In recent years, diatomaceous earth have received significant interest for pollutant removal. Diatomaceous Earth have high surface area, low-cost, easy accessibility, good mechanical resistance, and availability in large quantities. Defluoridation research has previously been done in batch experiments with natural adsorbents. The sorption ability of adsorbents determined by batch equilibrium is useful in providing basic information about the adsorbents effectiveness. None the less, the results of batch studies may not be applicable to continuous processes in which the contact time required to achieve equilibrium is insufficient. As a result, various studies show that continuous processes mode (fixed-bed column set-up) yields reliable information about breakthrough time, sufficient adsorption conditions, and adsorption efficiency stability, which can then be used to assess the capacity of prepared adsorbents for industrial applications. As a result, conducting adsorption experiments in a flow-through device is of interest. The primary goals was to (i) interrogate the fluoride sorption potential of Diatomaceous Earth and Activated Diatomaceous Earth in a fixed-bed column setup, (ii) compare the adsorption properties of adsorbent, and (iii) compare the adsorption properties with and without activation of DE (iii) evaluate fluoride adsorption mechanisms as a function of solution $\mathrm{pH}$, adsorbent particle size, and flow rate, (iv) investigate the adsorption processes further using mathematical calculation such as given by the Adams-Bohart and Thomas models, and (v) finally check the models' suitability for the design of flow-through systems can be checked. Fluoride is removed from aqueous solutions using this method.

\section{MATERIAL AND METHODS}

\section{Materials}

Diatomaceous Earth samples were collected in this study from mines in Barmer, Rajasthan State, India, about 50-100 kilometers east of Barmer and Jodhpur city Centre. Since these rocks are readily accessible in about a fifth of the total area of Rajasthan, they are a favored adsorption material due to their low supply costs.

\section{Sample preparation}

Natural deposits in Rajasthan's Barmer and Jodhpur districts provided the DE for the study. A part of the sample was cleaned with DDW or demineralized water. Centrifugation was used to separate colloidal particles from the suspension. Preliminary functional experiments were performed to test the DE heated up to a temperature at $110^{\circ} \mathrm{C}$ for 6 to $8 \mathrm{~h}$ in an oven. "Then cooled in a desiccator before being crushed in a mortar until the particles passed through a 250-m test sieve and placed in corked bottles to avoid moisture absorption"1.

\section{Preparations of Adsorbents}

The Diatomaceous Earth samples were washed with deionized water several times before all water-soluble compounds and dust were removed, then dried at $55^{\circ} \mathrm{C}$ for 48 hours. After allowing samples to cool to room temperature, "sample was crushed and sieved into three different mesh sizes: silt $(0.075 \mathrm{~mm})$, fine sand $(0.075-0.425 \mathrm{~mm})$, and medium sand $(0.425-2.00 \mathrm{~mm})$ "4. For later usage, all prepared samples were sealed in airtight plastic bags and placed in a cold, dry location.

\section{Preparations of Adsorbate}

Before use, all glassware and bottles were thoroughly cleaned and rinsed with deionized water. An analytical grade chemicals are used in experimental study. Fluoride standard solution freshly developed by mixing $2.21 \mathrm{gm}$ anhydrous $\mathrm{NaF}$ in $1000 \mathrm{~mL}$ of deionized water. "After diluting the stock solution, the required concentrations of synthetic fluoride were obtained"14. The $\mathrm{pH}$ of the fluoride solution used in the column experimental experiments was modified as required "with $0.1 \mathrm{M}$ $\mathrm{HCl}$ or/and $0.1 \mathrm{M} \mathrm{NaOH}$ solutions" ${ }^{\text {. }}$.

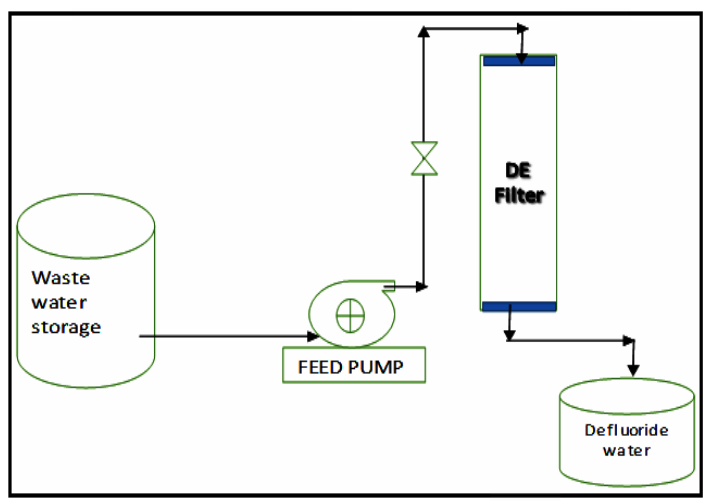

Fig. 1. Experimental Lab scale setup of Diatomaceous Earth adsorbent filter 


\section{Column Adsorption Experimental Set-Up and Procedures}

The dynamic behavior of fluoride removal using diatomaceous earth was assessed using continuous fixed-bed column adsorption studies. Continuous flow adsorption experiments was carried out in a small-scale cylindrical column with an empty bed volume of $515 \mathrm{~cm}^{3}$ and an internal diameter of $8.1 \mathrm{~cm}$. "A weighted volume of adsorbent of various particle sizes (silt: $0.075 \mathrm{~mm}$, fine sand: $0.075-0.425$ $\mathrm{mm}$, and medium sand: 0.425-2.00 mm) was added to the column"13. When regulating parameters like $\mathrm{pH}$ and flow rate were checked, the same particle size was used. To ensure a tightly packed adsorbed surface, the bed was conditioned with deionized water ( $\mathrm{pH}$ : 7.00-7.30) for $12 \mathrm{~h}$ (overnight) and to avoid the potential occurrence of voids, channeling, or cracking, which can significantly affect the performance of the column. To prevent channelling caused by gravity, a synthetic fluoride solution with a concentration of $10 \mathrm{mg} / \mathrm{L}$ was pumped into a packed bed column in up-flow mode. The influent volumetric flow rate differed between experiments, but an adjustable peristaltic pump (MS-REGLO, Labortechnik-Analytic, Zürich, Switzerland) was used to keep it constant in each one. The analysis done at room temperature $\left(25^{\circ} \mathrm{C}\right)$. An automated fraction collector was used to collect the effluent column sample (RFI, MA-RON GmbH, Germany). Collecting and quantifying the effluent solution at regular intervals confirmed the steady flow rate. When the fluoride concentrations in the effluent exceeded $90 \%$ of their initial levels, the column activity was halted. Fluoride concentrations was quantify using ion selective Electrode (makeHach, U.S.A model HQ440D). Inline dilution, inline dialysis, eluent degasser, $\mathrm{CO}_{2}$ suppressor, and chemical suppressor were used to measure fluoride concentrations in the calibration range of $0.2-200 \mathrm{mg} / \mathrm{L}$. Fluoride ion detection sensitivity is increased by suppression in IC, whereas red fluoride ion detection sensitivity is increased by red fluoride ion suppression. The maximum tolerable breakthrough concentration (Cb) was $1.5 \mathrm{mg} / \mathrm{l}$, which is the maximum appropriate amount for drinking water as recommended by the WHO. The impact of experimental parameters including particle size (silt: $0.075 \mathrm{~mm}$, fine sand: $0.075-0.425 \mathrm{~mm}$, and medium sand: $0.075-0.425 \mathrm{~mm}$ ), influent solution $\mathrm{pH}$ $(2.00,4.00$, and 6.00$)$, and influent volumetric flow rate $(1.25,2.50$, and $3.75 \mathrm{~mL} / \mathrm{min})$ on breakthrough behavior and fluoride removal was investigated.

\section{General procedure \\ Adsorbent characterizations \\ Crystalline structures}

An X-ray diffractometer (XRD-7000, Drawell, Shanghai, China) was used to examine the crystalline structures of the adsorbents using CuK $\alpha$ as a radiation source (1.54056) generate at $30 \mathrm{kV}$ and $25 \mathrm{~mA}$. With a phase width of 2 and a scanning rate of $0.04 / \mathrm{min}$, the diffractograms was obtained.

\section{Chemical composition}

"Using inductively coupled plasma-optical emission spectroscopy, the elemental composition of the adsorbents was determined (ICP-OES). The powder composition of the adsorbent materials was evaluated by X-ray fluorescence (XRF) spectroscopy"6.

\section{RESULTS AND DISCUSSION}

\section{Scanning electron microscopic study of Adsorbent}

Scanning and recorded at CDU lead detector with an instrument supplied by Hitachi $X-650$ scanning electron micro analyzer at an output power of $25 \mathrm{kV}$ examining the structure of DE at the surface. Every pinnate diatom had a series of rectangular pores arranged in a regular pattern along the void tubes, as shown in Figure 2/3.

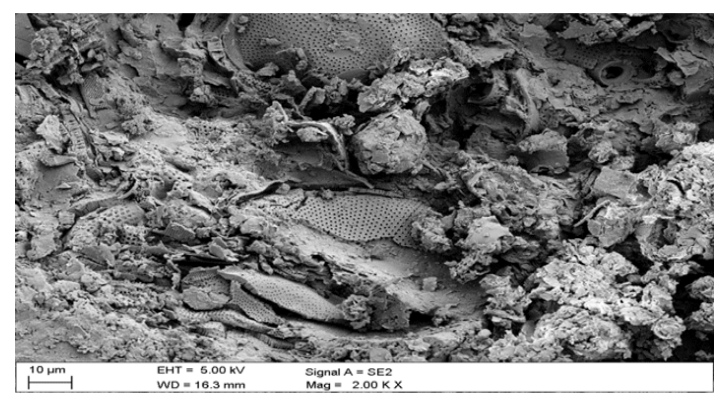

(a) Raw diatomaceous earth sample SEM image,

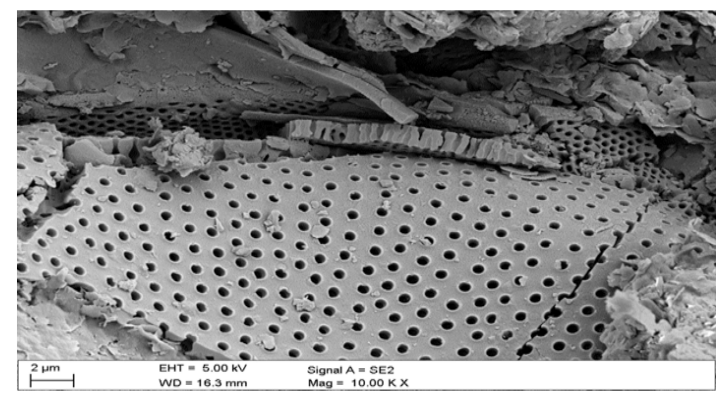

(b) SEM image of the porous structure of DE.

Fig. 2/3. shows a scanning electron microscope view of diatomaceous earth 


\section{Physicochemical analysis of adsorbent}

Analyzing samples were added to a particle size of $75 \mathrm{~m}$ in a milling pot of tungsten carbide. To assess the loss of weight on Ignition (LOI) values, samples was heated up to a temperature of $100^{\circ} \mathrm{C}$ in an oven and further in muffle furnace up to a temperature of $1,000^{\circ} \mathrm{C}$. To develop suitable fused glass bead, one $\mathrm{gm}$. of "sample was mixed with
$6 \mathrm{~g}$ of lithium tetra borate flux and fused at $1,050^{\circ} \mathrm{C}$. The sample was mixed with PVA binder and pressed in an aluminum cup at 10 tonnes for trace element analyses"1. Table 1 shows the effects of the main element composition in terms of percentage oxide. The DE's major component is silica $\left(\mathrm{SiO}_{2}\right)$ and $\mathrm{Al}_{2} \mathrm{O}_{3}$ while other components are minor in quantity, according to the findings. $\mathrm{DE}$ without metals has a chemical formula $\mathrm{SiO}_{2} \cdot \mathrm{nH}_{2} \mathrm{O}$.

Table 1: Physico-chemical parameters of DE and conc. of trace materials in DE

\begin{tabular}{|c|c|c|c|c|c|}
\hline Oxide & Composition (\%) & Tracee element & Concentration $(\mathrm{mg} / \mathrm{kg})$ & Trace element & Concentration $(\mathrm{mg} / \mathrm{kg})$ \\
\hline $\begin{array}{l}\mathrm{SiO}_{2} \\
\mathrm{Al}_{2} \mathrm{O}_{3}\end{array}$ & $\begin{array}{c}84.17 \\
4.01\end{array}$ & $\begin{array}{l}\text { Sc } \\
Y\end{array}$ & $\begin{array}{c}3.85 \\
51.45\end{array}$ & $\begin{array}{l}\mathrm{Pr} \\
\mathrm{Th}\end{array}$ & $\begin{array}{c}13 \\
13.7\end{array}$ \\
\hline $\mathrm{CaO}$ & 0.24 & $\mathrm{Cr}$ & 11.84 & Sm & 9.65 \\
\hline $\mathrm{P}_{2} \mathrm{O}_{5}$ & 0.04 & $\mathrm{La}$ & 58.5 & $\mathrm{Yb}$ & 6.24 \\
\hline $\mathrm{LOI}^{\mathrm{a}}$ & 7.52 & $\mathrm{Ni}$ & 7.38 & $\mathrm{Gd}$ & 8.42 \\
\hline $\mathrm{Fe}_{2} \mathrm{O}_{3}$ & 2.96 & $\mathrm{Rb}$ & 44.67 & $\mathrm{Ta}$ & 5.04 \\
\hline $\mathrm{Na}_{2} \mathrm{O}$ & 0.61 & $\mathrm{Zn}$ & 86.93 & Dy & 9.41 \\
\hline $\mathrm{TiO}_{2}$ & 0.17 & $\mathrm{Nb}$ & 85.41 & Lu & 0.89 \\
\hline $\mathrm{MnO}$ & 0.04 & $\mathrm{Sr}$ & 26.74 & $\mathrm{Hf}$ & 11.32 \\
\hline $\mathrm{K}_{2} \mathrm{O}$ & 0.75 & $\mathrm{Cu}$ & 17.55 & $\mathrm{Tm}$ & 0.91 \\
\hline $\mathrm{MgO}$ & 0.11 & $\mathrm{Zr}$ & 453.15 & $\mathrm{~Tb}$ & 1.48 \\
\hline $\mathrm{pH}$ & 8.68 & Co & 1.43 & Ho & 2.05 \\
\hline WRC & 2.25 & Mo & 2.36 & $\mathrm{Er}$ & 6.13 \\
\hline $\mathrm{Lo}^{\mathrm{la}}$ & 7.52 & Cs & 1.2 & $\mathrm{Eu}$ & 0.9 \\
\hline \multicolumn{2}{|c|}{ Loss on ignition } & $\mathrm{Ba}$ & 30.97 & $\mathrm{~Pb}$ & 11.08 \\
\hline \multicolumn{2}{|c|}{$\mathrm{Ph}$ at point-of-zero-charge } & $\mathrm{V}$ & 25.2 & $\mathrm{Nd}$ & 49.75 \\
\hline \multicolumn{2}{|c|}{ Water retention capacity $(\mathrm{mL} / \mathrm{g})$} & $\mathrm{Ce}$ & 19.58 & U & 2.95 \\
\hline
\end{tabular}

\section{$X$-ray diffraction analysis}

"A PAN analytical X'Pert Pro powder diffractometer with an X'Celerator detector and variable divergence- and fixed receiving slits with $\mathrm{Fe}$ filtered Co-K was used to analyze the DE for mineral composition. The phases were identified using the X'Pert High score plus app"7. "The material is fully amorphous, with no crystalline minor phases"1, according to DE's diffractogram as shown below.

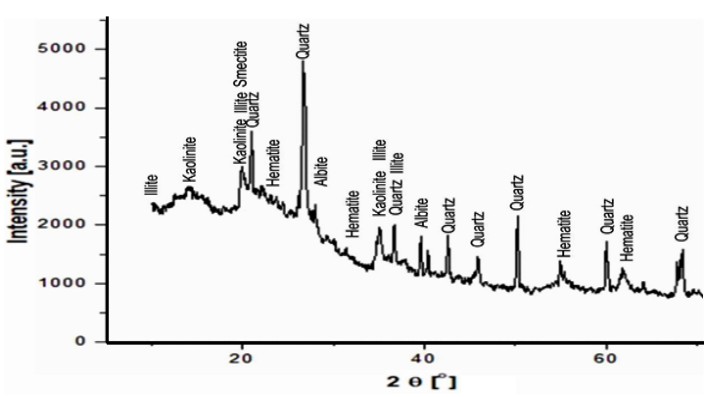

Fig. 4. X-ray diffraction patterns of a raw diatomite sample from Barmer mines deposit

\section{BET analysis}

"The pore depth, surface area and pore width of DE particles with a diameter of $250 \mathrm{~m}$ were calculated using the Brunauer-Emmett-Teller
(BET) method. Micrometrics TriStar II Surface Area and Porosity measurements ${ }^{1,4}$ are shown in Table 2 as well"1.

Table 2: showing Surface dimension of DE by BET

Porosity analysis of DE by BET

Parameters

$\begin{array}{lll}\text { Area } & \text { Volume } & \text { Pore } \\ \left(\mathrm{m}^{2} / \mathrm{g}\right) & \left(\mathrm{cm}^{3} / \mathrm{g}\right) & (\mathrm{nm})\end{array}$

Single point surface area $\quad 30.834$

BET surface area Single $\quad 31.126$

point adsorption

Total volume Adsorption $\quad 0.08032$

Average pore width 10.2564

(4 V/A by BET)

\section{FTIR spectroscopy}

The ALPHAFT-IR Spectrophotometer was used to conduct a Fourier rework infrared (FTIR) evaluation of the raw $D E$ and $D E$ with fluoride contained in order to distinguish the functional organizations within the cloth ${ }^{1}$. The Si-O-H spreading vibration is described by the $453 \mathrm{~cm}^{-1}$ transmittance, whilst the transmittance at $1,1 / 2 \mathrm{~cm}^{-1}$ represents the Si-O-Si spreading vibration. At $453 \mathrm{~cm}^{-1}$ and $1,1 / 2 \mathrm{~cm}^{-1}$, the uncooked DE and fluoride-loaded 
DE bands overlap, indicating that fluoride sorption at the DE floor is low. There become no enormous distinction with inside the purposeful training of the authentic fabric after fluoride sorption (Figure 5).

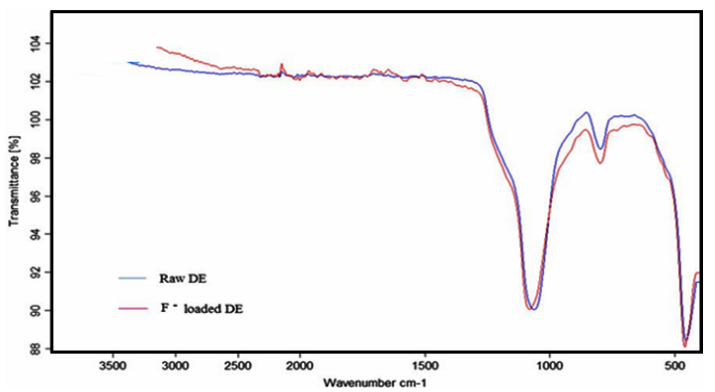

Fig. 5. Raw and F loaded DE FTIR spectrum

\section{Batch adsorption experiment}

The batch adsorption equilibration approach was used to investigate fluoride adsorption on DE. $50 \mathrm{~mL}$ of Fluoride solutions was pipetted out in a plastic bottle of $250 \mathrm{~mL}$ size. $0.1 \mathrm{M} \mathrm{HCl}$ or $0.1 \mathrm{M}$ $\mathrm{NaOH}$ were used to calibrate the $\mathrm{pH}$, and different masses of adsorbent were weighed into the bottles while keeping track of quantity of acid or alkali used. By adding deionized water, amount of the solution was increased up to $50 \mathrm{~mL}$. "After dilution, a solution containing $10 \mathrm{mg} / \mathrm{L}$ fluoride had a final concentration of $8 \mathrm{mg} / \mathrm{L}$. Corked bottles were shaken in a water bath shaker"1. With a thermo stated reciprocating motion. The suspensions was mixing at 5,000 rpm for $5 \mathrm{~min}$ after equilibration in a centrifuge machine. TISAB III was applied to the supernatants at a 1:10 volume ratio to decomplex any potential of iron (III) or aluminum fluoride complexes, avoid ionic strength variations, and maintain a pH between 5.2 and 5.5 . For a full reaction, the ingredients were stirred and allowed to sit for 1 hours. By Using ion-selective electrode (Hack, HQ440D,U.S.A make fluoride ion meter by selective electrode) cross checked with fluoride standard. "Fluoride was calculated in supernatants containing TISAB III at a volume ratio of $1: 10$, as in the samples"1. fluoride removal.

Eq. (1) was used to measure the percent Fluoride removal $(\%)=\frac{\left[c_{o}-c_{t}\right]}{c_{o}} \times 100$

"Whereas $\mathrm{C}_{0}(\mathrm{mg} / \mathrm{L})$ is the initial concentration of fluoride and $C_{e}(\mathrm{mg} / \mathrm{L})$ is the equilibrium concentrations of fluoride"1.

\section{Determination of $\mathrm{pH}$ and Point of Zero Charges (pHPZC)}

Adsorbents $\mathrm{pH}$ was determined by using a digital $\mathrm{pH}$ metre in a ration of $1: 10$ by adsorbent and water, as per the standard procedure 6 . A SOP was used to determine the $\mathrm{pH}$ of the adsorbents at the point of zero charges (pHPZC). $250 \mathrm{~mL}$ of $0.01 \mathrm{M}$ $\mathrm{NaCl}$ solution was used as an electrolyte in a $298 \mathrm{~K}$ vessel, and $\mathrm{N}_{2}$ was bubbled through it to keep the $\mathrm{pH}$ intact by keeping $\mathrm{CO}_{2}$ from the air from dissolving. $25 \mathrm{~mL}$ electrolyte was applied to 6 Erlenmeyer flasks, and $\mathrm{pH}$ adjusted with $0.1 \mathrm{M} \mathrm{NaOH}$ or 0.1 $\mathrm{M} \mathrm{HCl}$ to the desired value $(2.00,4.00,6.00,8.00$, and 10.00). The same procedure and method were used for the blank electrolyte solution $(0.01 \mathrm{M} \mathrm{NaCl})$. Each beaker received $0.25 \mathrm{~g}$ of rock samples and was shaken for 48 hours. The filtered suspension final $\mathrm{pH}$ was determined. The point of zero charges ( $\mathrm{pHPZC}$ ) was discovered at the intersection point by plotting the initial $\mathrm{pH}$ vs. final $\mathrm{pH}$.

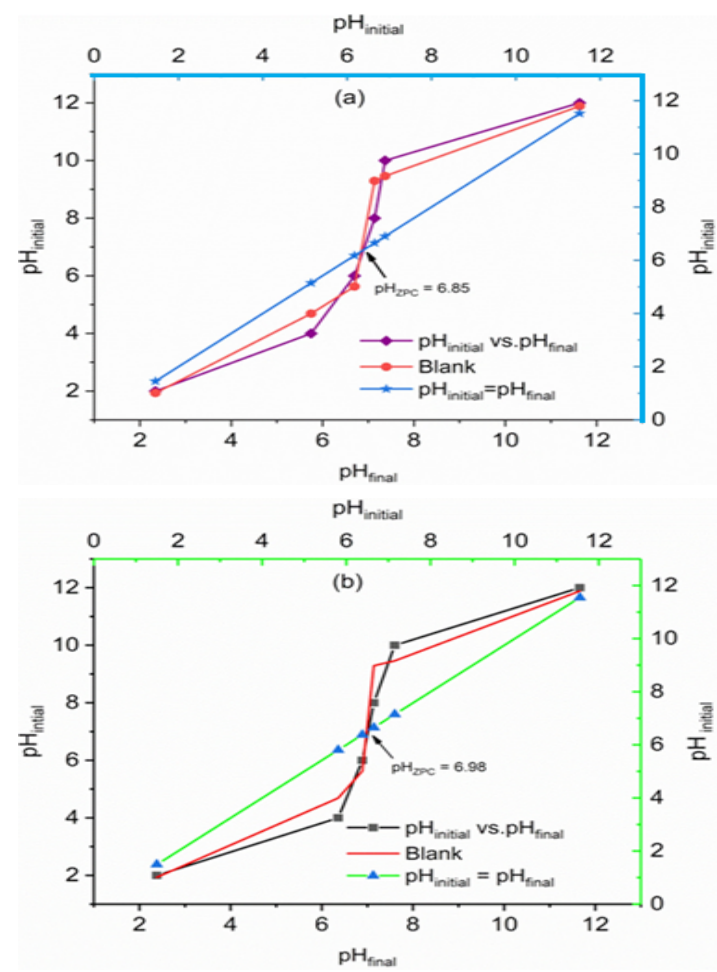

Fig. 6. Zero charge pH (pHPZC) determination for (a) Diatomaceous earth Raw and (b) Diatomaceous earth activated Adsorption experiment and equilibrium study

To test percent removal at optimum adsorption conditions, " $50 \mathrm{~mL}$ of $50 \mathrm{mg} / \mathrm{L}$ working standard solutions were used. The percentage of metal removal was examined separately by adjusting the $\mathrm{pH}$, adsorbent dose, contact time, and initial $\mathrm{M}(\mathrm{II})$ 
concentration in order to determine the optimum adsorption parameters for cadmium and lead. With adsorbent doses ranging from $50 \mathrm{mg}$ to $250 \mathrm{mg}$, the effect of $\mathrm{pH}$ on $\mathrm{M}(\mathrm{II})$ adsorption was investigated over a $\mathrm{pH}$ range of 2-7. Contact time for 30-150 min at the best adsorbent dose and $\mathrm{pH}$ was calculated using a rotatory shaking flask containing $M(I I)$. The effect of initial concentration in the range of $5-80$ $\mathrm{mg} / \mathrm{L}$ was investigated under ideal conditions. The percentage of Fluoride removal ${ }^{9}$ and the number of metal ions adsorbed per unit mass of adsorbent (qt) is calculated using the following formulas"2.

Fluoride removal $(\%)=\frac{\left[c_{o}-c_{t}\right]}{c_{o}} \times 100$

$q_{\mathrm{t}}=\frac{\left[c_{o}-c_{t}\right]}{2} \times \mathrm{V}$

Where $\mathrm{C}_{0}$ refers to the initial ion concentration of the metal ion, $\mathrm{C}_{\mathrm{t}}$ refers to the metal ion at $\mathrm{t}, \mathrm{V}$ indicates the initial ion solution volume $(50 \mathrm{~mL})$ and $\mathrm{m}$ indicates the adsorbent mass $(50 \mathrm{mg})$.

\section{Adsorption Kinetics}

Adsorption kinetics is investigated using kinetics models. For pseudo first order kinetics, Lagergren's equation is as follows.

$\log (q e-q t)=\log q e-\left(\frac{K 1}{2.303}\right) t$

Where $q_{t}$ means the amount of metal that has been adsorbed $(\mathrm{mg} / \mathrm{g})$ at any given moment, $q_{e}$ is the quantity of metal adsorbed at balance time $(\mathrm{mg} / \mathrm{g})$ and $\mathrm{K} 1$ represents the first order rate constant in pseudo $\left(\mathrm{min}^{-1}\right) 51$ represents the Ho equation for pseudo second order kinetics.

$\frac{t}{q_{t}}=\frac{1}{\left[K_{2} X q^{2} e\right]}+\frac{t}{q e}$

"Where, $\mathrm{K}_{2}$ = Pseudo second order rate constant (g/mg $\mathrm{min})$ "3.

\section{Adsorption Isotherm}

"Langmuir and Freundlich adsorption isotherm models 51 were used to express the adsorption isotherm"6.

The Langmuir model can be stated as follows:

$\frac{C_{e}}{Q_{e}}=\frac{1}{\left[q \operatorname{Lxk}_{\iota}\right]}+\frac{C_{e}}{q L}$

The Langmuir monolayer adsorption strength of the adsorbent is $q_{L}(\mathrm{mg} / \mathrm{g})$, and the Langmuir adsorption constant is $\mathrm{k}_{\mathrm{L}}(\mathrm{L} / \mathrm{mg}) . \mathrm{q}_{\mathrm{e}}$ is the number of metal ions added per mass of adsorbent $(\mathrm{mg} / \mathrm{g})$ at equilibrium time te. The difference between the initial concentration $\left(\mathrm{C}_{\mathrm{i}}\right)$ and the concentration of metal ions extracted is known as Ce-Equilibrium concentration $\left(C_{t}\right)^{\prime 2}$.

Observed Langmuir isothermal data are Error! Not a valid link. Table 3 showing calculated Langmuir parameters.

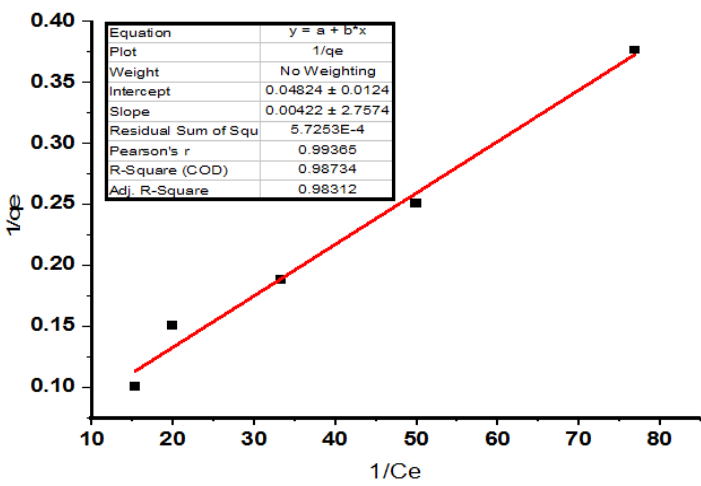

Fig. 7. Langmuir Adsorption isotherm for adsorption of fluoride on Raw Diatomaceous Earth Powder at $300 \mathrm{~K}$ and $\mathrm{pH}$ 2.0. Contact time $4 \mathrm{~h}$ and fluoride concentration $4 \mathrm{mg} / \mathrm{L}$

The Freundlich isotherm is described as follows:

$\log q e=\log K f+\frac{1}{n} \log C e$

Where, $\mathrm{K}_{\mathrm{F}}$-Freundich constant, 1/nheterogeneity factor.

Observed Freundlich parameters are Table 4: showing calculated Freundlich parameters

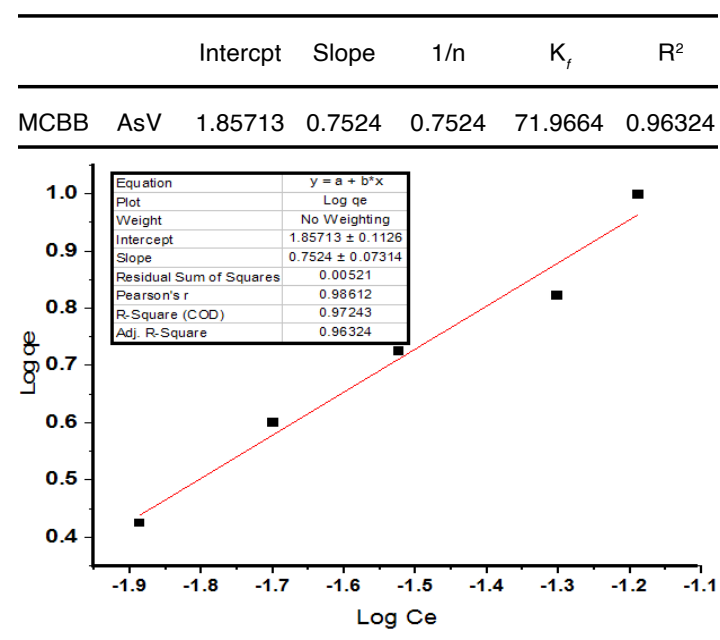

Fig. 8. Freundlich Adsorption isotherm for adsorption of fluoride on Activated Diatomaceous Earth Powder at $300 \mathrm{~K}$ 
This study about to removal of fluoride from aqueous solutions of treated waste water was examined in a continuous fixed-bed adsorption column system using Diatomaceous Earth as a filtering media and Activated Diatomaceous Earth as a absorbent. The characterizations investigations were performed using XRD, SEM, FTIR, BET, $X R F$, and ICP-OES equipment to reveal the mechanisms of adsorption and the suitability of the adsorbents for fluoride removal. The pHPZC is 6.98 for raw DE when used as a filtering media and 6.85 for Activated DE when used as a adsorbent. The effects of process parameters such as adsorbent particle size, influent $\mathrm{pH}$, and influent volumetric flow-rate on the performance of the adsorption process in a column were evaluated. "At a particle size of 0.075-0.425 $\mathrm{mm}$ and $0.075 \mathrm{~mm}$, respectively, at a lower solution $\mathrm{pH}(2.00)$ and flow rate $(1.25 \mathrm{~mL} / \mathrm{min})$ "2. Raw DE had a maximum removal capacity of $20.73 \mathrm{mg} / \mathrm{kg}$ and Activated DE had a maximum removal capacity of $71.97 \mathrm{mg} / \mathrm{kg}$. The increase in adsorbent particle size, solution $\mathrm{pH}$, and flow rate decreases the breakthrough and saturation time of the column bed and, consequently, lowers the amount of fluoride removal by raw $D E$. The breakthrough and exhaustion time on Activated DE was high at a particle size of $0.075-0.425 \mathrm{~mm}$, at lower solution $\mathrm{pH}$ and flow rate similar to that of raw DE. Thus, in order to attain optimum performance, suitable experimental parameters are significant for the operation of the adsorption column. "The Thomas and Adams-Bohar models were applied to estimate the breakthrough curves and to determine fixed-bed column kinetic parameters" 3 . Both the Adam-Bohar and the Thomas models could predict very well the entire region of the breakthrough curves for the fluoride reduction through Activated $D E$ and fluoride-reduction by raw DE used as a filtering media. The results show that raw $D E$ and Activated DE could be used in a fixed-bed adsorption column for the removal of excess fluoride from water. Although the adsorbents are inexpensive, an overall cost analysis of the purification system is critical because it has consequences for the adsorption method's viability (both technically and economically). To confirm that the defluoridation of groundwater and treated waste water using Diatomaceous Earth is a safe and sustainable process, additional testing of the adsorbents is needed, including representative samples tests for potential compositional, mineralogical, and textural changes in time due to weathering, leaching tests, competitive ions effects, and regeneration options.

\section{CONCLUSION}

The fluoride removal from treated waste water was examined in a continuous fixed-bed adsorption column system in this study. Diatomaceous Earth was used as a filtering media and as an adsorbent to remove fluoride from water. The pHPZC is 6.98 for raw DE when used as an adsorbent and 6.85 for Activated DE as a filter. The removal capacity of $20.73 \mathrm{mg} / \mathrm{kg}$ for raw. DE and $71.97 \mathrm{mg} / \mathrm{kg}$ for Activate DE were achieved at a particle size of $0.075-0.425 \mathrm{~mm}$. Thus DE is a suitable and easily available adsorbent used for defluoridation of water.

\section{ACKNOWLEDGEMENT}

Authors convey gratitude to SUNRISE University Alwar, Rajasthan (India), IET College Alwar, Rajasthan (India), and Dr. Pankaj Gupta sir for their guidance and support for providing instrumental facility for the research work.

\section{Conflicts of Interest}

The authors declare no conflict of interest.

\section{REFERENCES}

1. Anthony, I.A.; Gitari, M.W.; Gumbo, R.J, Desalination and Water Treatment., 2016, 36, 16745-16757.
2. Mishra, K.U.; Siddiqi, A.; Meikap, H, J. Cleon. Prod., 2021, 279,123645.

3. Mishra, K.U.; Siddiqi, A.; Meikap, H, J. Cleon. 
Prod., 2020, 381, 120917

4. WHO Guideline for drinking water, $4^{\text {th }} \mathrm{ed}$, Geneva, ISBN., 2011, 978, 154815

5. Rango, T.; Vengosh, A.; Whitford, G.M, Sci. Total Environ., 2017, 596-597, 1-11

6. Demelas, H.; Beyene, A.;, Abebe, Z.; Melese, A, BMC Public Health., 2019, 19, 1298

7. Cai, J.; Zhang, Y.; Pan, B.; Zhang, W, Water Res., 2016, 102, 109-116.

8. Mohan, S.; Kumar, V.; Singh, D.K.; Hasan, S.H, RSC Adv., 2016, 6, 87523-87538.

9. Araga, R.; Kali, S.; Sharma, C.S, Clean Soil Air Water., 2019, 47, 1-9.

10. Khan, M.I.; Chang, Y.; Sustainability., 2018, 10, 2567

11. Saha, P.; Shinde, O.; Sarkar, S, Int. J. Phytoremed., 2017, 19, 87.

12. Ali, S.; Abbas, R.Z, Sustainability., 2020, 12, 1960.
13. Ali, M.E.; Hoque, M.E.; Hossain, S.K.; Biswas, M.C, Int. J. Environ. Sci. Technol., 2020, 1, 24.

14. Baby, R.; Saifullah, B.; Hussein, M.Z, Nanoscale Res. Lett., 2019, 14, 34.

15. Morejón, L.; Delgado, J.A.; Ribeiro, A.A.; Oliveira, M.V.; García, E.M.I.; Alfonso, A.; Poh, P.; Griensven, M.V.; Balmayor, E.R, Int. J. Mol. Med. Sci., 2019, 20, 1790.

16. Yang, Y.Y.; Jiang, J.; Kang, W, J.Environ Manag., 2018, 206, 929-937.

17. Lingamdinne, L.P.; Koduru, J.R.; Karri, R.R, Intech., 2019, 805, 122-127.

18. Hoang, L.P.; Nguyen, T.M.P.; Van, H.T.; Hoang, T.K.D.; Vu, X.H.; Nguyen, T.V, Water Air Soil Pollut., 2020, 231, 28.

19. Tsuzuki, T.; McCormick, P.G, Acta Mater., 2000, 48, 2795.

20. Bassem, S.M.; Biodiversity Int J., 2020, 4, 10. 